\title{
Future-Proof Human Capabilities: Raising the Future Employability of Graduates
}

\author{
Marcus S. Bowles* \\ Professor \\ University of Tasmania \\ Adjunct, Tasmanian Institute for Learning and Teaching \\ Locked Bag 1341, Launceston, Tasmania, 7250, Australia \\ Nicola I. Bowes \\ Chief Engagement and Development Officer \\ Queensland Tertiary Admissions Centre \\ Level 2, 11 Little Cribb Street, Milton, Queensland, 4064, Australia \\ Paul T. Wilson \\ KnowledgePatterns.com \\ GPO Box 1657, Hobart, Tasmania, 7001, Australia
}

\begin{abstract}
While many frameworks have emerged purporting to describe human skills, soft skills, employability skills, or future capabilities, there exists sparse research comparing these frameworks or isolating the most important skills within an Australasian future workforce context. Given the importance of using a skills framework to better analyse and predict future skills demand in the workforce, educators, employers and recruits need to better appreciate the value certain skills will hold over others in terms of future employability. Using a data-driven approach based on text analysis we will analyse the aggregate information contained in existing frameworks to discover the future capabilities. These future capabilities provide a framework and logic that allow us to more flexibly examine the relationship between people and jobs, and to create a taxonomy that allows us to create capability stacks that confirm the requirements for a future learning and work.
\end{abstract}

Keywords: capability, future work, graduate employability, soft skills, human capabilities, tacit knowledge, Latent Dirichlet Allocation, capability stacks

\section{Introduction}

There has been an increased preponderance of frameworks seeking to define the employability skills, soft-skills, enterprise skills, or human capabilities relating to work in the fourth industrial age (Moore \& Morton, 2017). This has occurred as it becomes apparent the concept of a 'job' and how tasks are organised into work are changing and educators and governments need to better identify the skills that raise employability (AlphaBeta, 2019)(Benbow \& Hora, 2018). The main stimulus for this disruption is the effect Artificial Intelligence (AI) and automation have on how work is organised and performed. As the speed of this disruption increases, flow-on effects like job losses, augmentation of technology within existing jobs, and creation of completely new jobs become apparent. This is paralleled by widening recognition of the need to grow non-technical, human skills and better target education, workforce, and industry development strategies.

Many research projects purport to have identified the essential human capabilities required for future employment. This work uses a text analysis and data-driven approach to analyse and validate the Queensland Tertiary Admissions Centre (QTAC) Human Capability Framework (HCF) with other frameworks that have also been derived through global, evidence-based research. The aim being to derive the most relevant, globally portable set of capabilities required for future learning and work.

\section{Introducing Capability Frameworks}

Capability Frameworks are strategic. They have been used for over three decades by organisations seeking to build more agile, future oriented workforce plans that not only provide the umbrella strategy to grow current job competencies and performance, but also develop people beyond the 'job' to grow the potential productive capability of the entire workforce (Bowles \& Schoenheimer, 2009) (Lui, et al, 2018). 
This means capability frameworks are built to provide a high-level insight into the skills, knowledge, personal attributes and mindsets required for future work and life success, not just task-level performance. To do this capability frameworks of necessity have to emphasise both explicit knowledge (codified and portable) that can be taught, and the tacit knowledge (implicit and embedded in a context) that cannot be taught but must be acquired through situated experience (Bowles \& Lanyon, 2016).

Capability Frameworks extend competency models (behavioural or technical) to develop and assess personal dimensions such as emotions and cognitive factors (so-called 'mindsets' or 'intellect' in some taxonomies). In Australasian employment or education policy settings these non-technical, human capabilities have alternatively been called transferable skills, employability skills, soft skills, enterprise skills, common competencies, professional practice capabilities, or core capability standards. With the latest research showing over 63 percent of future job profiles will be based on human skills, these frameworks increasingly focus on verification of soft skills (Deloitte Access Economics, 2017)(World Economic Forum, 2016)(Deloitte, 2019).

Figure 1 Capability dimensions (after Bowles \&Schoenheimer, 2009)

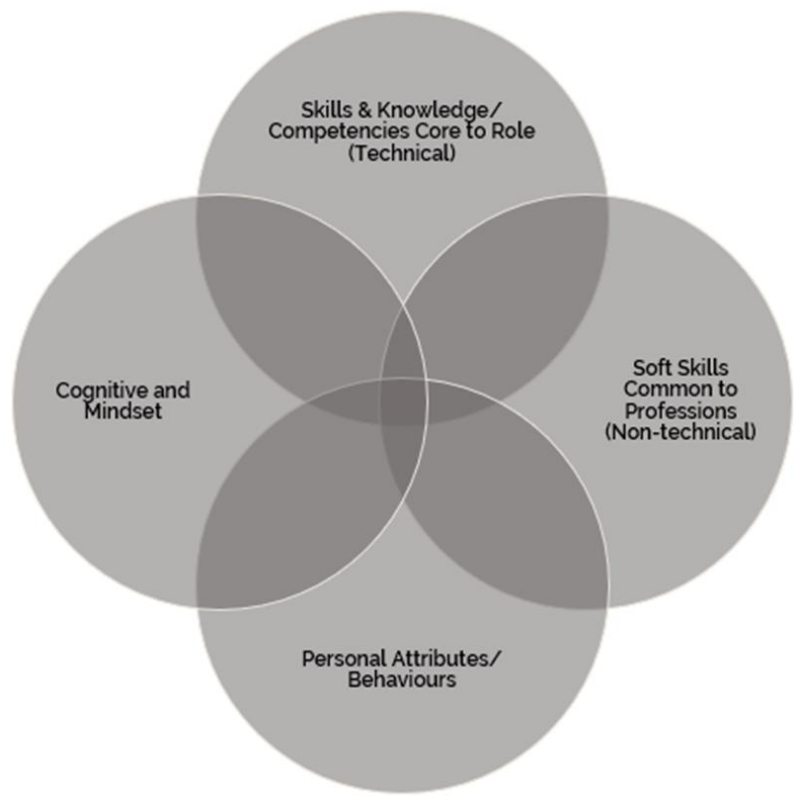

More recently, tertiary institutions have begun to adopt Capability Frameworks to help build future-oriented curriculum. These frameworks focus on ensuring that tertiary education is optimised to develop the capabilities that the workers of the future will need to flourish in the fourth industrial age (Moore \& Morton, 2017)(Benbow \& Hora, 2018). Capability Frameworks can map the capabilities required for entry to tertiary education, recognising capabilities that are developed during courses, and the capabilities which are ascertained upon graduation.

One such Human Capability Framework was commissioned by the Queensland Tertiary Admissions Centre (QTAC). QTAC aims to use this Framework to provide schools and its university and vocational education members with access to a common currency of capabilities that can be used to streamline entry and credit into tertiary courses. The QTAC Human Capability Framework (QTAC-HCF) was developed in collaboration with The Institute for Working Futures (Working Futures ${ }^{\circledR}$ ) to define the capabilities integral to higher education and required for the future workforce. The QTAC-HCF, version 3.0, was released for workplace validation in November 2018.

An early model benchmarked by the QTAC-HCF was the work done by DeakinCo. around measuring capabilities within professional practice and leadership. DeakinCo. identified ten core professional capabilities that were aligned to levels on the Australian Qualification Framework (AQF). These levels and the ten core capabilities were also mapped to a range of corporate models used to define levels of work or remuneration (i.e. Stratified Systems Theory)(Jaques, 1997), competency models used in certain industries or vocational educational and training packages (i.e. the Skills Framework for the Information Age) (SFIA 2019), and development frameworks (i.e. the Dreyfus and Dreyfus level model) (Dreyfus \& Dreyfus, 1986).

There is such a proliferation of future capability and employability skills frameworks already in existence or currently under development that readers could be forgiven for being confused and overwhelmed. It should be recognised, however, that most of these frameworks are identifying the same core human capabilities. 
Although terminology and categorisation differ between frameworks, the majority are in fact describing the same common core of capabilities. Internationally there is broad agreement amongst experts in education, training, industry, technology and government about what human skills workers need to flourish in the fourth industrial age.

As a result of initial consultation and research the QTAC-HCF identified fourteen capabilities:

1) Personal Initiative and Drive

2) Personal Learning and Mastery

3) Adaptive Mindset

4) Cultural and Social Intelligence

5) Empathy

6) Entrepreneurial Thinking

7) Ethics and Integrity

8) Communication

9) Collaboration and Relationships

10) Creativity and Innovation

11) Critical Thinking and Judgment

12) Problem Solving

13) Digital Acumen

14) Customer Focus

Each capability has a description and set of indicators confirming seven levels of proficiency.

QTAC's goal in developing another framework was to capture the 'core' capabilities essential in the future workplace. To do this, Working Futures ${ }^{\circledR}$ developed a draft framework which was then compared to five major future-focused global capability frameworks which were each based on recent research. The draft QTAC-HCF was also compared to the graduate attribute frameworks for twenty-nine Australian universities, and five employee frameworks from major private and public organisations. Each of the comparison frameworks was considered able to offer a vision of the capabilities required for future learning and work. This comparison determined which future-focused capabilities were core to these frameworks, even if the terminology or categorisation differed. This paper presents the outcomes of this comparison.

\section{Data-Driven Approach: Capability Framework Analysis}

Conceptually, a capability framework is like a map. Given the broad array of human capabilities we might observe, it provides an organising scheme for classifying and describing those capabilities. This then provides a basis for activities such as:

- Assessing and influencing the human capabilities available in a context (e.g. an industry, region, or organisation) over time;

- Identifying, assessing and improving processes that support capability development;

- Anticipating, assessing and responding to capability gaps (both excesses and shortages) that might exist or emerge;

- Mapping capabilities to certain types of work or roles; and

- Assisting individuals in the assessment and development of their own portfolio of capabilities.

The QTAC-HCF is a new capability framework developed to classify capabilities of university entrants. In this context a focus towards the future is essential. However, at the outset with a newly developed capability framework, how might it be usefully assessed to identify any gaps, overlaps, or potential refinements?

The approach taken in this research was to apply the QTAC-HCF as an organising map for classifying the capability content of other capability frameworks. At a conceptual level, this is like analysing how one map captures the relevant features of a repertoire of other maps.

The logic of this approach was that these other frameworks were also designed to provide a full explanation and classification of human capabilities, and therefore their coverage and alignment with regard to the QTAC capabilities could yield useful insights about the QTAC capabilities.

This approach is like combining multiple low-resolution maps to create one high-resolution map. For example, instead of the 20 statements about innovation-related capabilities in the QTAC-HCF, the expanded data-set contained around 800 innovation-related capability statements. And overall, instead of assessing the 464 QTAC-HCF capability statements in isolation, the expanded data-set encompassed more than 6000 capabilities, providing a rich network of capability descriptions, concepts and relationships. This meant that, by utilising text and data analysis techniques, the QTAC-HCF could be evaluated in the following ways: 
- Coverage of a QTAC-HCF capability would be indicated by the number of capability statements that closely or substantially matched that capability;

- Overlaps would be indicated by the number of capability statements that closely or substantially matched more than one QTAC-HCF capability; and

- Gaps would be indicated by capability statements that had no close or substantially matched QTAC-HCF capability.

In addition, refinements could also emerge from researcher-originated insights during the analysis process, or via focussed data analysis on patterns of coverage, overlaps or gaps identified.

\section{The Capability Framework dataset}

To create the expanded capability framework dataset, frameworks were selected that either emphasised themes relevant to the QTAC-HCF's purpose, or represented other important capability domains that might reveal a robust and different perspective on coverage, overlaps or gaps. Thematically, these included:

- Future skills-focussed capability frameworks - Australian and international capability frameworks with a specific research-based focus on future capabilities given the challenges of automation and change. The specific frameworks included are outlined in Table 1 below. They include:

○ Deakin Digital;

- OECD Global Workforce Core Competencies;

○ DET Core Skills for Work Developmental Framework;

$\circ$ World Economic Forum, Top 10 Future Skills in 2020; and

$\circ$ Australian Industry and Skills Committee, Future Skills and Training.

- Australian university graduate capabilities and outcomes - given that the purpose of the QTAC-HCF is to evaluate the capabilities of prospective university entrants, the capabilities that universities aim to develop in their graduates are particularly relevant; some alignment would be expected, and capabilities at the graduate level also represent a stepping stone towards the corporate and public service capability frameworks that become relevant as a graduate's career progresses. Using desktop research, publicly available frameworks were sought from all Australian universities, with 29 being located and added to the analysis dataset. These tended to be quite concise capability statements, reflecting their general nature, without the different capability levels and detail of a full corporate or public service capability framework.

- Australian public service and industry capability frameworks - these were included to help bring out the full range of capability types and themes being considered in Australian organisations, and thereby a broad view of QTAC-HCF coverage, gaps or overlaps. Thematically, they also classify capabilities applied in a broad career context - rather than in an education and development phase - and so they tend to contain more detail, more levels, and a more diverse range of capability statements. The specific frameworks included were:

- NSW Public Service Capability Framework (2019)

○ Victorian Public Service Commission (capability.vic.gov.au) (2019)

○ World Economic Forum, Future of Jobs (2016)

- Department of Education, Victoria - Employability Skills (2006)

o Australian Core Skills Framework (2012) 
Table 1 Comparative employability and future skill frameworks

\begin{tabular}{|c|c|c|c|c|}
\hline DeakinCo. ${ }^{1}$ & $\begin{array}{l}\text { OECD Global } \\
\text { Workforce Core } \\
\text { Competencies } \\
(\text { OECD, 2014) }\end{array}$ & $\begin{array}{l}\text { DET, Core Skills for } \\
\text { Work Developmental } \\
\text { Framework } \\
\text { (DET, 2015) }\end{array}$ & $\begin{array}{l}\text { World Economic } \\
\text { Forum, Top } 10 \text { Future } \\
\text { Skills in } 2020 \\
\text { (WEF, 2018) }\end{array}$ & $\begin{array}{c}\text { Australian } \\
\text { Industry \& Skills } \\
\text { Committee, } \\
\text { Future Skills and } \\
\text { Training } \\
\text { (AISC, 2017) }\end{array}$ \\
\hline $\begin{array}{c}\text { Self-management } \\
\text { Communication } \\
\text { Teamwork } \\
\text { Problem Solving } \\
\text { Critical Thinking } \\
\text { Digital Literacy } \\
\text { Global Citizenship } \\
\text { Innovation } \\
\text { Professional Ethics } \\
\text { Emotional Judgement }\end{array}$ & $\begin{array}{c}\text { Analytical thinking } \\
\text { Flexible Thinking } \\
\text { Strategic Thinking } \\
\text { Manage Resources } \\
\text { Achievement Focus } \\
\text { Diplomatic Sensitivity } \\
\text { Teamwork \& Team } \\
\text { Leadership } \\
\text { Organisational } \\
\text { knowledge \& } \\
\text { alignment } \\
\text { Negotiating and } \\
\text { Influencing }\end{array}$ & $\begin{array}{c}\text { Manage career and } \\
\text { work life } \\
\text { Work with roles, } \\
\text { rights and protocols } \\
\text { Communicate for } \\
\text { work } \\
\text { Connect and work } \\
\text { with others } \\
\text { Recognise and utilise } \\
\text { diverse perspectives } \\
\text { Plan and organise } \\
\text { Make decisions } \\
\text { Identify and solve } \\
\text { problems } \\
\text { Create and innovate } \\
\text { Work in a digital } \\
\text { world }\end{array}$ & $\begin{array}{c}\text { Complex problem } \\
\text { solving } \\
\text { Critical thinking } \\
\text { Creativity } \\
\text { People management } \\
\text { Coordinating with } \\
\text { others } \\
\text { Emotional intelligence } \\
\text { Judgment and } \\
\text { decision making } \\
\text { Service orientation } \\
\text { Negotiation } \\
\text { Cognitive flexibility }\end{array}$ & $\begin{array}{c}\text { Collaborating } \\
\text { Foundation Skills } \\
\text { Learning and } \\
\text { Adapting } \\
\text { Entrepreneurship } \\
\text { Analytical } \\
\text { Value Creating } \\
\text { Non- } \\
\text { Automatable } \\
\text { Social } \\
\text { Platforming } \\
\text { Digital }\end{array}$ \\
\hline
\end{tabular}

\section{Data Analysis: Classification Methodology}

The core analysis methodology was supported by building a suite of text and topic classification tools to allow the QTAC-HCF classifications to be applied across the 6000+ indicators in the dataset. This involved creating a means to:

- Maintain a "keyword" set of words and phrases for each QTAC-HCF classification, where the presence of a word or phrase in a data-set capability indicator implied a match to a QTAC-HCF capability.

- Automate the application of these keyword sets across the dataset, thereby yielding a full set of data-set capability indicators matched to (zero, one or more) QTAC-HCF capability indicators. (Allowing zero, one or more matches catered for the possibility of gaps or overlaps in the application of the QTAC-HCF to the dataset).

- Apply multiple text analysis techniques to help the data researcher evaluate and refine the keyword sets for each QTAC-HCF capability. This involved checking both the matched and unmatched sets of documents for each QTAC-HCF capability using various text and statistical analysis techniques, including:

○ Chi-Square Keyword Extraction; (Matuso \& Ishizuka, 2003)

○ KeyGraph Keyword Extraction;(Ohsawa, Benson, \& Yachida, 1998)

$\circ$ Latent Dirichlet Allocation; (Blei, Ng, \& Jordan, 2003) and

$\circ$ Term Frequency-Inverse Document Frequency.

This set of analytical tools was built on the Knime Analytics Platform (www.knime.com).

With this toolset established, the data researcher used it to conduct an iterative process of populating the keyword sets for each QTAC-HCF capability. This involved setting keywords, running the automated classification process, using the analysis toolset to check for misclassifications, and then refining the keyword sets and iterating this process. The process was concluded when no misclassifications were identified by the data researcher. A final step in this phase was an additional set of iterations based on a review of data-set indicators that had not been classified to any QTAC-HCF capability, to confirm they sat outside the classification - or refine and iterate the keyword sets to include them. It is useful to briefly explain the role of the keyword sets in the text analysis. The underlying logic of this approach is that any sentence (or, in this case, capability indicator) is an incomplete rendering of some concepts we're trying to communicate. This means there are many ways to describe 'innovation' or any other capability concept.

${ }^{1}$ The DeakinCo. Professional Practice Credentials and underpinning professional standards can be accessed at https://www.deakinco.com/credentials 14 
In the context of text analysis, this means the same 'innovation' concept might be represented by a variety of words and arrangements thereof. In effect, given that this analysis was concerned with ascertaining the broad coverage of the 14 capability concepts in the QTAC-HCF, mentions of 'innovation' in different capability frameworks all referred to the same broad 'innovation' concept. Extending this equivalence to other concepts, matching between QTAC-HCF capabilities and data-set capability indicators via keywords was done in this way.

\section{Data Analysis: Evaluating Classifications}

With the QTAC-HCF classifications applied to the dataset, the next step involved evaluating the classifications and the relationships between them. This involved Latent Dirichlet Allocation (LDA) analysis of:

- Each classification

LDA is a method for topic extraction from a set of documents based on the words they contain (Blei, $\mathrm{Ng}, \&$ Jordan, 2003). Turisi and Silipo (2018) describe it as a way to "discover novel, previously unknown topics in a collection of texts without a-priori knowledge". Conducting LDA on the capability indicators related to each QTAC-HCF capability yielded clusters of (sub) topics encompassed within that QTAC-HCF capability. These sub-topics could then be reviewed to assess the overall coverage of each QTAC-HCF capability.

\section{- Pairwise classification overlaps}

Using the analysis toolset, it was possible to conduct LDA analysis of only data-set indicators that co-occurred in each combination of QTAC-HCF capabilities. The LDA topics for these overlapping indicators could then be reviewed to assess any implications or insights for refining the QTAC-HCF capabilities.

- Unclassified indicators

Around 800 indicators in the dataset were not assigned to any QTAC-HCF capability. These were analysed, reviewed and considered as part of the main classification process, and included data-set indicators that were not sufficiently related, or too specific or too general to be meaningfully related to a QTAC-HCF capability. An LDA analysis of these was also conducted to check for any important topics within these indicators.

This phase of LDA-enabled analysis allowed for specific exploration of the QTAC-HCF capability overlaps and gaps. In particular, the LDA-defined topic clusters provided an effective way to identify common conceptual themes and assess their relevance to the QTAC-HCF capabilities.

\section{Human Capability Framework Analysis and Conclusions}

The overlap and comparative analysis conducted on the QTAC-HCF indicated a few duplications and several overlaps where indicators are based on the same key words. Most significant was the coverage of learning, career planning and development across the first two capabilities, 01. Personal initiative and drive and 02. Personal learning and mastery. The coverage of ethics and values was also noted to cause overlap in in 01. Personal initiative and drive and 07. Ethics and Integrity.

The extent of keyword correlations can be depicted at a very granular level, as represented by the table below. This was achieved using an automated text analysis process to evaluate all the words of each capability indicator in the data-set, after excluding common 'stop words' (e.g. 'and', 'to', 'the') that would not contribute usefully to the analysis.

Significant correlations between capabilities are listed in Attachment 1. It was also possible to isolate the strongest correlations, indicating intrinsic relationships between certain capabilities (natural capability stacks or clusters). An analysis of co-occurrences was also completed to indicate the strongest overlaps and relationships between the QTACHCF capabilities. Such relationships can confirm where future relationships may lead to stacking or clustering related capabilities. 
Table 2 Strongest capability correlations and relationships

\begin{tabular}{|c|c|c|c|c|}
\hline \multicolumn{5}{|c|}{ Notable Correlations ( 0.2 or greater) } \\
\hline 0.35 & \multicolumn{2}{|c|}{ 10. Oreat ivity and Innovation } & \multirow{2}{*}{\multicolumn{2}{|c|}{$\begin{array}{l}\text { 06. Entrepreneurial Thinking } \\
\text { 04. Oultural and Social Int elligence }\end{array}$}} \\
\hline 0.31 & 05. Empathy & & & \\
\hline 0.25 & \multicolumn{2}{|c|}{ 11. Orit ical Thinking and Judgment } & \multicolumn{2}{|c|}{ 01. Personal Initiat ive and Drive } \\
\hline 0.22 & \multicolumn{2}{|c|}{ 08. Communication } & \multicolumn{2}{|c|}{ 01. Personal Init iativeand Drive } \\
\hline 0.21 & \multicolumn{2}{|c|}{ 07. Ehicsand Int egrity } & \multicolumn{2}{|c|}{ 04. Oultural and Social Intelligence } \\
\hline \multicolumn{5}{|c|}{ Lower but notable correlations (0.09-0.19) } \\
\hline 0.14 & 12. Problem Solving & & \multicolumn{2}{|c|}{ 11. Oritical Thinking and Judgment } \\
\hline 0.13 & \multicolumn{2}{|l|}{ 05. Empathy } & \multicolumn{2}{|c|}{ 03. Adaptive Mindset } \\
\hline 0.12 & \multicolumn{2}{|l|}{ 12. Problem Solving } & \multicolumn{2}{|c|}{ 10. Oreat ivity and Innovation } \\
\hline 0.12 & \multicolumn{2}{|c|}{ 06. Entrepreneurial Thinking } & \multicolumn{2}{|c|}{ 01. Personal Initiat iveand Drive } \\
\hline 0.11 & \multicolumn{2}{|c|}{ 11. Orit ical Thinking and Judgment } & 08. Communication & \\
\hline 0.11 & \multicolumn{2}{|c|}{ 07. Ehicsand Integrity } & 05. Empathy & \\
\hline 0.09 & \multicolumn{2}{|c|}{ 06. Entrepreneurial Thinking } & 03. Adaptive Mindset & \\
\hline
\end{tabular}

Most of the correlations displayed in Attachment 1 and table 2 are weak, as expected, because of the design work already done to establish distinct and meaningful QTAC-HCF capability definitions. Ordinarily such low correlations might be of little interest, though the particular text analysis approach outlined in this paper was designed to identify and explore these with a second level of analysis: the LDA analysis of overlaps and gaps. This analysis yielded automated (text-based) topic clusters to be produced - for example, the top 20 co-occurrences display some important relationships between capabilities included in the HCF (See Figure 2). It was possible to explore these overlaps at different levels of granularity by adjusting the number of topic clusters the LDA analysis was set to produce. For example, the following table shows some of the data-researcher's summaries the (30) topic clusters drawn from the data-set indicators that were not matched to any QTAC-HCF capability.

Table 3 Indicative examples of LDA topic clusters drawn from data-set indicators not matched to a QTAC-HCF capability.

\begin{tabular}{|l|}
\hline LDA Analysis - Topic Clusters - summary explanation of topic theme \\
\hline Topic 1 - Organisational / strategic goals and outcomes, plans, and project management. \\
\hline Topic 2 - Formal business themes - governance, standards re accounting, health \& safety, and quality. \\
\hline Topic 3 - Accounting, tax and financial concepts, analysis of financial reports \& admin documentation. \\
\hline Topic 4 - Identifying, measuring and responding to risk. \\
\hline Topic 5 - Long-term perspectives on alliances, markets, strategy and industry. \\
\hline
\end{tabular}

This LDA topic clustering of the unmatched items provided a way to assess the themes present, and to evaluate any implications for the QTAC-HCF capability set. The topics listed in table 3 were assessed as being strongly focussed on specific industry and contextual themes that didn't need to present in the QTAC-HCF.

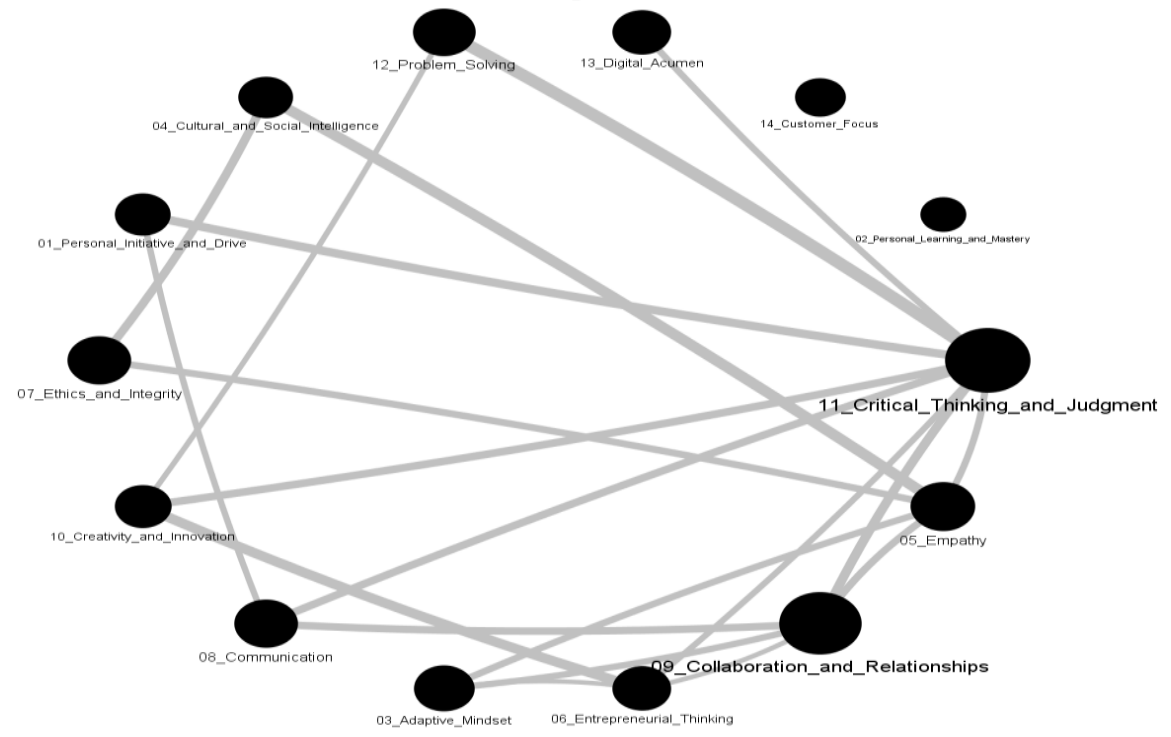

Figure 2 Top 20 co-occurrences across studied frameworks (Nodes scaled by overall number of co-occurrences) 


\section{Co-occurrences and Matching}

The co-occurrences and matching provide important insights that QTAC can use to assist universities seeking to deploy effective graduate attribute or capability frameworks that focus on graduate employability. While many universities across the globe and those that are members of QTAC have different ways to state and measure attainment of a graduate's employability, the foundations of employability centre on attainment of:

"A set of skills, knowledge and personal attributes that make an individual more likely to secure and be successful in their chosen occupation(s) to the benefit of themselves, the workforce, the community and the economy." (York, 2006: 21)

However, the exact nature of the graduate attributes or graduate learning outcomes that raise employability for graduates across different disciplines, locations and contexts is an ongoing topic of research and debate (Crisp \& Oliver, 2019; Oliver \& Jorre de St Jorre, 2018).

QTAC research has confirmed not only what human capabilities relate best to future work and employment, the resulting framework can be used to test and confirm the coverage of existing university frameworks listing graduate attributes. Such insights can inform future improvements of not only graduate attributes but evidence-based assessment of a graduate's readiness for future employment.

Table 4 on the following page shows where the QTAC-HCF capability has aligned coverage with other frameworks, university and corporate. Key word coverage is indicated with 1 , and no coverage with 0 .

Table 4 Classification of Indicators to QTAC-HCF Capabilities (multiple matches allowed)

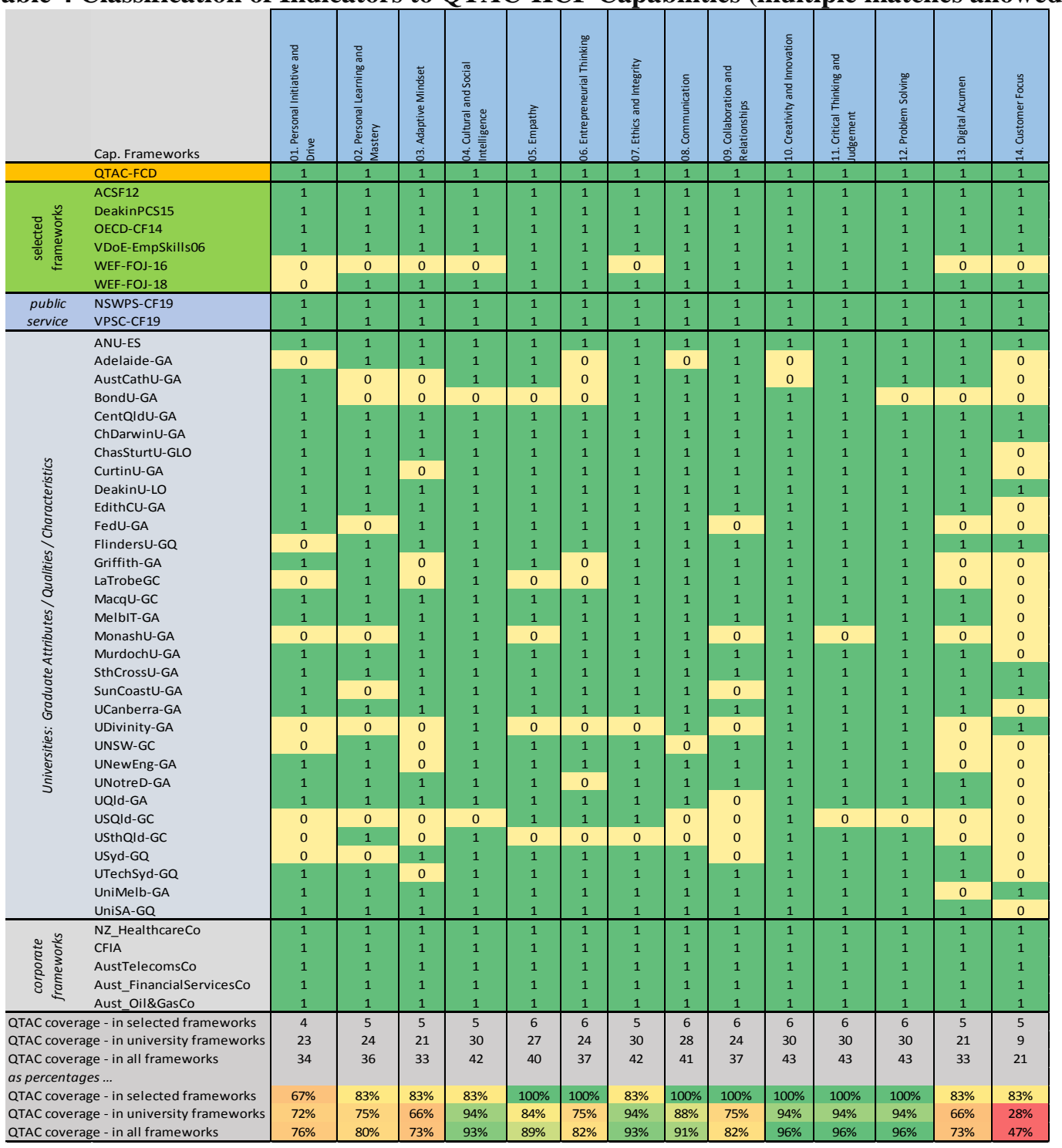




\section{Conclusion}

The research and analysis have uncovered a persistent conflict between rating capabilities based on how work is conducted today and the requirements for the future. Capabilities such as Customer Focus, Digital Acumen, Entrepreneurial Thinking and Cultural and Social Intelligence scored highly with industry experts and stakeholder workshops when framing future capabilities. Nonetheless, comparison with other frameworks using LDA and subsequent review with people asked to rate its importance to their current roles - using critical incident interviews and subject matter expert workshops - failed to rate these capabilities as important as all other capabilities in the QTACHCF (Bowles, 2019).

Isolating the top future capabilities was less difficult. The importance of eight future capabilities that were core to graduate employment was confirmed in comparative analysis with other capability frameworks. Later validation research with subject matter experts using a modified Delphi approach reinforced this original finding (Bowles, 2019).

After the results from the LDA validation and subsequent field tests and critical incident interviews resulted in a final list of fourteen validated QTAC Future Capabilities. These are listed in the following table from highest ranked to lowest ranked, in terms of comparative frequency and perceived importance.

\section{Table 5 QTAC Validated Future Capabilities}

\section{Capabilities} Description

Generic Core - All roles, all levels of work and stage of career progress

\section{Communication}

2. Collaboration

4. Problem Solving

5. Ethics

6. Adaptive Mindset

7. Empathy

8. Lifelong Learning
Able to communicate with clarity and impact to facilitate individual and collective understanding, action or information exchange.

Able to work collaboratively with all types of people, contribute to teamwork and to build relationships and networks across a range of people or groups.

Able to use a range of tools or methods to critically examine and assess existing information, thinking, assumptions and issues to present wellreasoned insights or to make judgements.

Able to define and analyse problems, generate optimal solutions and make recommendations.

Able to act with integrity and in conformance with social and professional standards of ethical conduct.

Able to adjust to change and maintain their curiosity while dealing with disruption, pressure and setbacks in a resilient, positive manner.

Able to recognise and regulate their own emotions in any situation and is good at identifying and respecting the needs and feelings of other people.

Able to identify and continuously develop one's own knowledge, skills and personal attributes such as mindset and motivation.

Common Core - Role dependent, all levels of work and career stages

Able to appreciate personal strengths and weaknesses and effectively relate

9. Initiative and Drive others in a professional manner. This includes being able to work independently, being motivated and accepting responsibility their own actions.

Able to be entrepreneurial and make connections between disparate ideas,

10. Innovative Thinking challenge current thinking or practices, and actively uses knowledge to create new products, solutions or opportunities.

Able to actively contribute to creative works, ideas or novel solutions.

11. Creativity

12. Cultural Awareness

Able to engage with others with sensitivity and regard for diversity and the social or cultural differences impacting behaviour.

13. Digital Acumen Able to use digital technology to undertake workplace tasks and outcomes.

14. Customer Focus the customer experience. 
The first eight capabilities have been identified as essential or core human capabilities required for future employability; irrespective of the person, or their employer, industry, job, level of work, or location. While the last six are critical to securing employment in the future workforce, their relative importance will vary depending on the job role and the context (employer, industry, profession, or location).

\subsection{Future deployment}

Once finalised, the Framework, including the descriptions and indicators across the levels of proficiency, will be made available to education providers under a creative commons license allowing free use for educational purposes.

This research will inform three parallel initiatives. Firstly, organisations will be permitted to map their credentials or informal learning programs against the Framework. This will provide a common language around human or soft skills to enhance recognition of prior learning or experience to an agreed standard.

Secondly, by determining an individual's capability using the Human Capability Framework, admissions advice and guidance can be enhanced for applicants not possessing an Australian Tertiary Admissions Rank (ATAR) score that is based on academic achievement at school.

Uncovering and recording capability stacks will be another benefit to government, businesses, educational providers and students. Further research will be initiated to identify how the capabilities can stack into clusters that optimise readiness of graduates to enter job neighbourhoods where modelling is showing technology will create or stimulate sustainable employment opportunities. It will also facilitate the creation of targeted programs to assist workers in jobs being fully automated or augmented by technology, enabling them to complete a capability assessment to determine how their current capabilities can be developed to open more sustainable employment opportunities. In this approach, opportunities for employment are identified through mapping jobs that share similar capability requirements. This is possible through knowledge of the stack of related capabilities that optimise future employment opportunities within a defined job neighbourhood. It will also help graduates avoid educational and career paths tied to jobs that are known to be at substantial risk from automation by the time they graduate. This offers important opportunities to improve people's individual career prospects, and also to maintain and grow overall workforce productivity in a rapidly changing work and technological environment.

\section{References}

AlphaBeta (2019). Future Skills, Google Australia: Sydney Retrieved May 2019 at https://www.alphabeta.com/wpcontent/uploads/2019/01/google-skills-report.pdf;

Australian Industry and Skills Committee [AISC] (2017). Future skills and training: A practical resource to help industry future skills and training, Commonwealth of Australia: Canberra. Retrieved 18 March 2019 at https://www.aisc.net.au/sites/aisc/files/documents/Future\%20Priority\%20Skills\%20Resource.pdf

Benbow, R.J. \& Hora, M.T. (Winter, 2018). Reconsidering college student employability: A cultural analysis of educator and employer conditions of workplace skills. Harvard Educational Review, 88(4): 483-515.

Blei, D.M., Ng, A.Y. \& Jordan, M.I. (2003). Latent Dirichlet Allocation. Journal of Machine Learning Research, 9931022.

Bowles, M. \& Schoenheimer, H. (2009). Developing Human Capability. Andermark, Sydney.

Bowles, M., Lanyon, S. (2016). Demystifying credentials: Growing capabilities for the future, DeakinDigital and Deakin University: Melbourne. Retrieved 12 March 2019 at https://www.deakinco.com/uploads/dc_whitepaper_demystifying_credentials_v01_FA\%20(3).pdf

Bowles, M. (June 2019). Validation report: Human Capability Framework, Queensland Tertiary Admissions Centre: Brisbane.

Crisp, G. \& Oliver, B. (2019). Re-imagining graduate achievement and employability in J. Higgs et al. (Eds.), Education for Employability: Learning for Future Possibilities(Volume 1). Brill Sense, pp. 73-82. Retrieved May 2019 at https://brill.com/view/book/edcoll/9789004400832/BP000015.xml

Deloitte (2019). The path to prosperity: Why the future of work is human, Building the Lucky Country \#7, Deloitte Insights: Sydney. Retrieved 6 June 2019 at https://www2.deloitte.com/au/en/pages/building-lucky-country/articles/path-prosperity-future-work.html

Deloitte Access Economics (May 2017). Soft skills for business success, Deloitte and DeakinCo.: Melbourne. Retrieved 13 March 2019 at https://www2.deloitte.com/au/en/pages/economics/articles/soft-skills-business-success.html;

Department of Education \& Training [DET] (2015). Core Skills for Work Developmental Framework, Department of Education, Employment and Workplace: Canberra Australia. Retrieved 18 March 2019 at https://docs.education.gov.au/node/37103 
Dreyfus, H.L. \& Dreyfus, S.E. (1986). Mind over Machine: the power of human intuition and expertise in the era of the computer, Basil Blackwell, Oxford.

Jaques, E. (1997). Requisite Organization: Total System for Effective Managerial Organization and Managerial Leadership for the 21 st Century, Gower London.

Lui, R., Agrawal, B., Vempaty, A., Sherchan, W., Sin, S., \& Tan, M. (June 2018). Date-driven job capability profiling. AIED2018International Conference on Artificial Intelligence in Education, 187-192. DOI: 10.1007/978-3319-93846-2_34

Matuso, Y. \& Ishizuka, M. (2003). Keyword extraction from a single document using word co-occurrence statistical information. International Journal on Artificial Intelligence Tools, 13(1), 157-169. Retrieved 28 July 2019 at: https://pdfs.semanticscholar.org/de66/e457cfb0c7a6ff6fbc72b1ee6cd79c883f2d.pdf

Moore, T., \& Morton, J. (2017). The myth of job readiness? Written communication, employability, and the "skills gap" in higher education. Studies in Higher Education, 42(3): 591-609. doi: 10.1080/03075079.2015.1067602

OECD (2014). OECD Core Competency Framework, Office of Talent, OECD: Paris. Retrieved 18 March 2019 at https://www.oecd.org/careers/oecdcorecompetencies.htm

Oliver, B. \& Jorre de St Jorre, T. (2018). Graduate attributes for 2020 and beyond: recommendations for Australian higher education providers. Higher Education Research \& Development,37(4): 821-836.

SFIA Foundation, Skills Framework for the Information Age Foundation, 7.0. Accessed 18 March 2019 at https://www.sfia-online.org/en/framework/sfia-7.

Ohsawa, Y., Benson, N.E., \& Yachida, M (April 1998). KeyGraph: automatic indexing by co-occurrence graph base on building construction metaphor. Proceedings of the Advances in Digital Libraries -ADL'98, IEEE International Forum on Research and Technology, 12-18. DOI:10.1109/ADL.1998.670375.

Organisation for Economic Cooperation and Development [OECD] (2014). Competency Framework, accessed online 21/01/2019 at https://www.oecd.org/careers/competency_framework_en.pdf.

Turisi, V. \& Silipo, R. (2018). Topic Detection with Text Mining, KnimeTV, accessed online 9 April 2019 at https://www.slideshare.net/KNIMESlides/topic-detection-with-text-mining-in-knime-analytics-platform97383034.

World Economic Forum [WEF] (2016). The future of jobs: Employment, skills and workforce strategy for the Fourth Industrial Revolution, WEF, Geneva. Retrieved 14 March 2019 at http://www3.weforum.org/docs/WEF_Future_of_Jobs.pdf;

World Economic Forum (2018). The future of jobs report, Insight report, Centre for New Economy and Society, Geneva. Retrieved 18 March 2019 at http://www3.weforum.org/docs/WEF_Future_of_Jobs_2018.pdf

Yorke, M. (2006). Employability in Higher Education: What It Is - What It Is Not, The Higher Education Academy United Kingdom, Heslington, York, United Kingdom.

\section{Attachment 1: Capability key word correlation table}

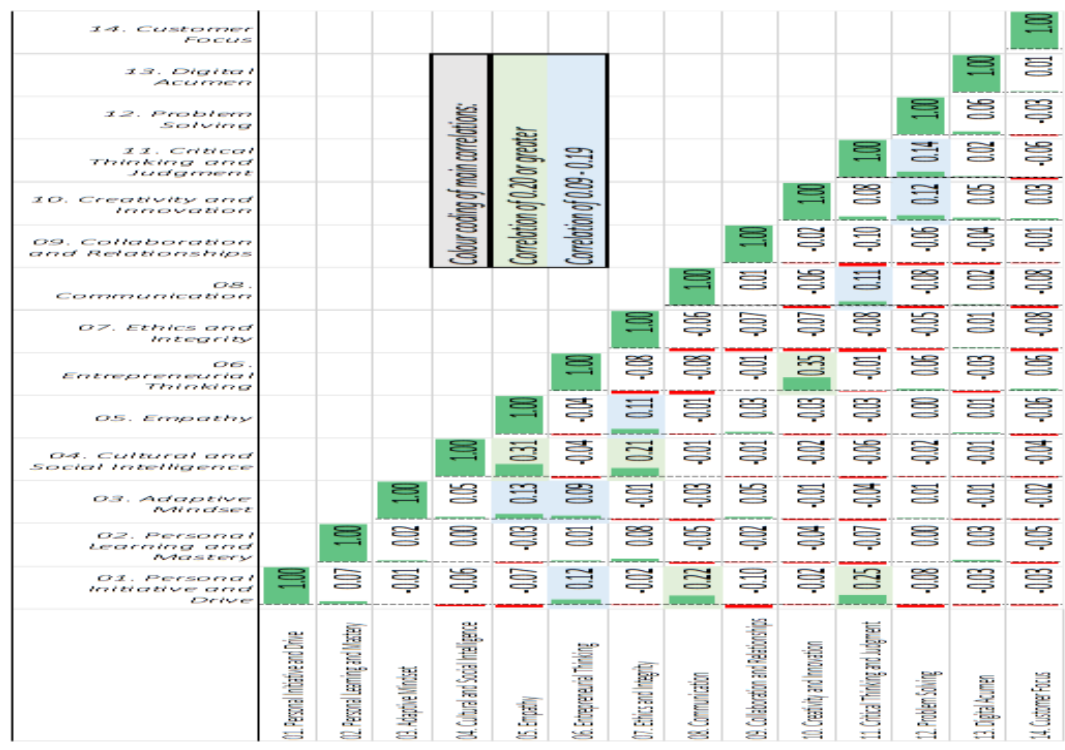

